\title{
DISCUSSION
}

\section{A NOTE ON FORMAL DISCIPLINE}

\author{
E. A. KIRKPATRICK \\ State Normal School, Fitchburg, Mass.
}

Professor F. C. Lewis' article on this topic in the School Review for April, I905, is an interesting and valuable contribution, but it is not the last word. I do not expect to say the last word, nor do I expect it to be said for many years yet. I wish, however, to suggest a point of view that may be in the direction of a solution of the problem.

Professor Lewis' transference of the general effects of special training from the intellect to the will is, in the judgment of the writer, a partial, but only a partial, solution of the question. Even in the plane of consciousness it is not certain that general intellectual as well as volitional modifications may not be produced by special learning processes. But in these days of research into the subconscious we must recognize that many modifications of mind are deeper and more fundamental than conscious states.

If we take the physiological view-point, light is thrown on the question. Experiments have shown that exercising one arm increases the size of the other, and that increase in sensory discrimination and motor skill is not confined to the portion of skin or the digit exercised, but is shown especially in the corresponding parts on the other side, and to a less extent in other parts, especially adjacent ones. These and other facts support the view that in every reaction, especially in new adjustments, all parts of the nervous system are active, though the chief activity is in certain parts immediately concerned, and in a less degree in other parts closely connected with them, while the activity of other parts is perhaps so small as not to be perceived except by special tests.

Now, all this activity produces effects which result in tendencies or habits. These we might name respectively as special, associated and general habits. In the sphere of mental activity, then, what we have called general habits may be designated as intellectual power or will-power, as one prefers; but in the narrower meaning usually attached to the words both are needed to describe the result. The important thing is to find out what kind of mental acts produce the most general effects. Here is where I wish to give my suggestion for further discussion and experiment.

We have every reason to believe that new acts, rather than those many times repeated, are most effective in this way; for as an act becomes a fixed habit the activity is confined more and more definitely to the special parts needed for its 
performance. It is useless, therefore, to expect to prove anything regarding general discipline by prolonged experiments upon special habits, as has been attempted; for the more nearly a habit is formed, the less are the general effects. The more promising field is to study the effect of dealing with a variety of situations upon the ability to deal with new situations of the same and of different kinds.

It seems quite probable that the most marked general effects will be in activities having the same general purpose-research in one line for research in other lines, making money in one industry for making money in others, inventions for other inventions, painting for ability in producing other forms of beauty.

The use of a variety of means for a certain purpose would seem likely to give the whole mind a trend in that direction which would enable it to act more effectively in meeting new situations for the same end, and for analogous ends. On the contrary, if only one mode of obtaining the general purpose is used, the tendency to reach it in other ways decreases, and the individual's activity is more and more confined to the one line.

Experimenters upon animals have been led from their observations to think it probable that an animal that has mastered one set of difficulties in getting out, or into a place where food is to be obtained learns to overcome other difficulties more readily. If this is true in the slightest degree of animals, which have little or no conscious power of generalization, it is probably true in a marked degree of man, who is able to go so readily from particulars to generals. It is in this higher process of learning, rather than in the lower automatic habits, that general effects are to be found, and in which they are probably intellectual as well as volitional.

If this view is correct, there must be considerable modification in the methods by which psychologists investigate the general effects of special activities. A beginning has already been made in the study of learning processes rather than of the practice of what has already been learned. Further study of this question may soon result in conclusions that will wholly modify our educational practices and cause our courses of study to be scientifically constructed so as best to prepare in a general way for life. Perhaps it may be proved that the practical subjects now being introduced in response to popular demand, and justified on economic and sociological grounds, are psychologically well suited to give a general and liberal preparation for life. It is not impossible that the acquisition of practical knowledge of several industries (something that has long been carefully avoided even by pronounced advocates of manual training) may be recognized as one of the best means of obtaining a general and liberal education for the life of today

Further study will also probably show us just how much justification there is for claiming general training from memory exercises and from exercises involving the going from particulars to generals and from generals to particulars.

Arguments for any form of general training in the future must not merely show what mental activities are called into play, but must prove that such activities produce general effects that increase the student's power to deal with other situations in accomplishing the purposes of the life of today. 
It seems probable that a variety of activities fundamentally related would give more general power than one general type of activity carried on for many years until what has been learned has taken the form of fixed habits. Fixed habits probably favor practical efficiency more than general mental development. We may find that some forms of thoroughness in education have results cxactly the opposite of those clain ed and desired by their advocates. On the other hand, the probability of varied training failing to go deep enough in its effects to give any permanent bent to the mind needs investigation.

I certainly agree with Professor Lewis that the subject of general discipline is decidedly a live topic, and one likely to have additional light thrown upon it in the near future, but I do not believe that the whole story can be obtained from consciousness and will; unconscious tendencies and conscious intellectual activities must also be questioned. His emphasis upon the teacher's influence upon the ideals of students is well placed, yet there is still reason to believe that there may be certain general tendencies produced by certain subjects and certain methods independent of the personality of the teacher. He is the most important factor in education, but, as a science, education must determine the nature and degree of general discipline produced by different subjects of study, regardless of who teaches them. 